Research Article

\title{
ZnO-Activated Carbon Blended as a Catalyst for Oxidative Desulfurization of Dibenzothiophene
}

\author{
Wega Trisunaryanti ${ }^{1, *}$, Satriyo Dibyo Sumbogo ${ }^{1}$, Safa Annissa Novianti ${ }^{1}$, Dyah Ayu \\ Fatmawati $^{1}$, Maria Ulfa ${ }^{2}$, Yatim Lailun Nikmah ${ }^{3}$
}

\begin{abstract}
${ }^{1}$ Department of Chemistry, Faculty of Mathematics and Natural Sciences, Gadjah Mada University, 55281, Daerah Istimewa Yogyakarta, Indonesia.

${ }^{2}$ Department of Chemistry Education, Faculty of Teacher Training and Education, Sebelas Maret University, 57126, Central Java, Indonesia.

${ }^{3}$ Department of Chemistry, Faculty of Science, Sepuluh Nopember Institute of Technology, 60111, East Java, Indonesia.
\end{abstract}

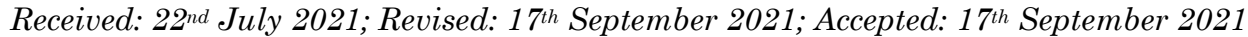
Available online: $20^{\text {th }}$ September 2021; Published regularly: December 2021

\section{Abstract}

The problem of sulfur content in heavy oil is a challenge for researchers to meet the needs of environmentally friendly fuels. The catalyst preparation plays an important role in the desulfurization process. The synthesis of $\mathrm{ZnO}$-activated carbon as a catalyst and its activity in oxidative desulfurization (ODS) reaction has been successfully carried out. In this work, the $\mathrm{ZnO}$ and activated carbon (AC) were blended by a solid-solid reaction. The $\mathrm{ZnO}$, $\mathrm{AC}$, and $\mathrm{ZnO}-\mathrm{AC}$ were then characterized using acidity test with pyridine vapor adsorption, Fourier Transform Infra-Red (FTIR), X-ray Diffraction (XRD), Scanning Electron Microscope-Energy Dispersive X-Ray (SEM-EDX), and Surface Area Analyzer (SAA). ODS of dibenzothiophene (DBT) reaction was performed by using $\mathrm{H}_{2} \mathrm{O}_{2}$ under variation of the reaction time $(30,60,120$, and $150 \mathrm{~min}$ ) for the ZnO-AC catalyst. The efficiency of ODS-DBT was analyzed by a UV-Visible spectrophotometer. The XRD analysis result showed that ZnO-AC blended displays new crystal peaks of $\mathrm{Zn}$ in the AC diffractogram. The surface area $\left(734.351 \mathrm{~m}^{2} / \mathrm{g}\right)$ and acidity $(4.8780 \mathrm{mmol} / \mathrm{g})$ of $\mathrm{ZnO}$ $\mathrm{AC}$ were higher than $\mathrm{ZnO}$ and $\mathrm{AC}$ themselves. ZnO-AC produced the highest efficiency of ODS-DBT which was 93.83\% in the reaction time of $120 \mathrm{~min}$. Therefore, the simple procedure of this physical blending was proved effective to homogenize between $\mathrm{ZnO}$ and $\mathrm{AC}$ into $\mathrm{ZnO}-\mathrm{AC}$ so that it has good physicochemical properties as an ODSDBT catalyst.

Copyright (C) 2021 by Authors, Published by BCREC Group. This is an open access article under the CC BY-SA License (https://creativecommons.org/licenses/by-sa/4.0).

Keywords: Oxidative Desulfurization; Dibenzothiophene; ZnO; Activated Carbon; Physical Blending

How to Cite: W. Trisunaryanti, S.D. Sumbogo, S.A. Novianti, D.A. Fatmawati, M. Ulfa, Y.L. Nikmah. (2021). $\mathrm{ZnO}$-Activated Carbon Blended as a Catalyst for Oxidative Desulfurization of Dibenzothiophene. Bulletin of Chemical Reaction Engineering \& Catalysis, 16(4), 881-887 (doi:10.9767/bcrec.16.4.11797.881-887)

Permalink/DOI: https://doi.org/10.9767/bcrec.16.4.11797.881-887

\section{Introduction}

As for 2040, International Energy Agency reported that energy and fossil fuel demands would still increase around 30\% [1]. The strict regulation towards sulfur content that cannot exceed more than $15 \mathrm{ppm}$ is one of the greatest

* Corresponding Author.

Email: wegats@ugm.ac.id (W. Trisunaryanti) difficulties in fulfilling the world demands on petroleum oil [1,2]. Hydrodesulfurization (HDS) has received great attention for the past years, this reaction involved the usage of hydrogen gas as well as high temperature and pressure [3]. Major drawbacks of this reaction are the relatively high cost of HDS due to the high usage of hydrogen and heat [4]. Another alternative for the sulfur removal process has been proposed, such as oxidative desulfurization, ultrasound- 
assisted oxidative desulfurization, extractive desulfurization, adsorptive desulfurization, biodesulfurization, and so on [3-6].

The oxidative desulfurization (ODS) technique has also gained large interest as an alternative to HDS due to its comparatively low cost, mild condition, and simplicity [1-4]. In ODS reaction, there are two steps involved in the process: the conversion of sulfur-containing compounds into their respective sulfoxides and sulfones, followed by extraction of these compounds using extractant [3]. The oxidation process required oxidants, such as $\mathrm{H}_{2} \mathrm{O}_{2}$ which is considered an environmentally friendly and green oxidant, and acid catalyst [6].

Several solid catalysts had been examined for ODS reaction including heteropoly acid, either alone or supported [7], and metal oxides, i.e. oxides of (Mo, Mn, Sn, Fe, Co, Zn) metals [8]. However, most of it either concerned complicated and multistep synthesis techniques or unrecyclable. The latest literature survey shows that $\mathrm{ZnO}$ was reported for adsorptive desulfurization [9] and $\mathrm{ZnO}$ was able to remove the sulfur content without changing the main hydrocarbon structure where non-sulfurcontaining crude fuel oil mass remains unchanged. Another study stated that the increment of the catalytic activity of $\mathrm{ZnO}$ can be corresponded to a lower band gap value $(3.35 \mathrm{eV})$ compared to $3.65 \mathrm{eV}$ for $\mathrm{Zn}_{5}(\mathrm{OH})_{8} \mathrm{Cl}_{2} \cdot \mathrm{H}_{2} \mathrm{O}$, which would increase the absorption capacity of higher wavelength radiation [10]. A novel percent of nano-catalyst with $18 \%$ zinc oxide $(\mathrm{ZnO})$ was an active component over nano-alumina for sulfur removal from kerosene fuel by air (oxidative desulfurization (ODS) method) [11]. Riad and Mikhail showed that Zn-incorporated hydroxyapatite catalysts were investigated towards oxidative desulfurization of light gas oil with a total sulfur content of $1281.8 \mathrm{ppm}$. The maximum observed sulfur removal reached $89.7 \%$ using zinc catalysts prepared via the ion exchange technique [12].

Currently, activated carbon (AC) has been found in an increasing number of catalytic reactions. It is used as either the support for the active phases or as the catalyst itself, because of its physical performance and surface functional groups, which contain oxygen [13]. For this reason, $\mathrm{AC}$ is selected as the support material for $\mathrm{ZnO}$ due to its effectiveness as a heterogeneous catalyst in $\mathrm{H}_{2} \mathrm{O}_{2}$ decomposition to form hydroxyl radicals which is a powerful oxidant [14]. In the ODS process, the hydroxyl radicals reacted with organic acids to form peracids and oxidized the organosulfur compounds to their corresponding sulfoxides and sulfones.
Several studies on the synthesis of $\mathrm{ZnO}-\mathrm{AC}$ have been carried out previously. Swat et al. synthesized $\mathrm{AC} / \mathrm{ZnO}$ as adsorbent through thermal co-precipitation for desulfurization of model diesel fuels (MDFs) at ambient temperature [15]. Meanwhile, Ahmed Zeki et al. produced $\mathrm{ZnO} / \mathrm{AC}$ composites also through thermal co-precipitation as a catalyst for ODS-DBT [16]. Khlaif et al. made $\mathrm{ZnO}$ Nanoparticles Loaded $\mathrm{AC}$ as an adsorbent in adsorptive desulfurization in crude oil through an impregnation process using an ultrasonic device [17]. As far as the authors know, no one has ever synthesized $\mathrm{ZnO}-\mathrm{AC}$ through the physical mixing of both materials as a catalyst for ODSDBT. This method is considered easier, simpler, and more applicable than the previously proposed method.

Therefore, in this research, a cost-effective catalytic oxidative desulfurization process was developed by preparing $\mathrm{ZnO}-\mathrm{AC}$ as a catalyst with a physical blending method together with hydrogen peroxide as oxidant and acetonitrile as an extraction solvent to produce a lower sulfur concentration.

\section{Materials and Methods}

\subsection{Materials}

Zinc oxide $(\mathrm{ZnO})$ and activated carbon (AC) were used for the catalyst preparation. The model fuel was made of $n$-hexane and dibenzothiophene. Hydrogen peroxide $30 \%(\mathrm{w} / \mathrm{w})$ was used as an oxidizing agent and acetonitrile was used as solvent extractant. All the materials were supplied by Merck.

\subsection{Preparation and Characterization of $\mathrm{ZnO}$ - $\mathrm{AC}$}

$\mathrm{ZnO}$ was blended with activated carbon (AC) with a weight ratio of $1: 9$, it was crushed and sifted through 100 mesh. The $\mathrm{ZnO}$-AC catalyst was then calcined at $500{ }^{\circ} \mathrm{C}$ for $5 \mathrm{~h}$ with an $\mathrm{N}_{2}$ gas of $20 \mathrm{~mL} / \mathrm{min}$. All catalysts $(\mathrm{ZnO}$, $\mathrm{AC}$, and $\mathrm{ZnO}-\mathrm{AC}$ ) were analyzed by X-Ray Diffractometer (Philips X'Pert MPD), Surface Area Analyzer (SAA, JW-BK112 Surface Area and Mesopore Size Analyzer), acidity test using pyridine gas as an adsorbate, and FourierTransform Infrared Spectrometer (FT-IR, Shimadzu IRPrestige-21). ZnO-AC was analyzed by Scanning Electron Microscope-Energy Dispersive X-Ray (SEM-EDX, Hitachi SU 3500).

\subsection{Acidity Test}

The acidity of $\mathrm{ZnO}, \mathrm{AC}$, and $\mathrm{ZnO}-\mathrm{AC}$ was tested using a gravimetric method of pyridine 
vapor adsorption. All of the samples were dried overnight at $105{ }^{\circ} \mathrm{C}$ until their mass was constant. This was done to release the vapor traps beneath the catalyst. The acidity value was calculated using Equation (1):

$$
\operatorname{Acidity}(\mathrm{mmol} / \mathrm{g})=\frac{\left(W_{2}-W_{1}\right) \times 1000}{\left(W_{1}-W_{0}\right) \times M W \text { of pyridine }}
$$

where $W_{0}$ is mass of empty porcelain crucible (g), $W_{1}$ is mass of porcelain crucible containing catalyst after oven $(\mathrm{g}), W_{2}$ is mass of porcelain crucible after adsorption (g), and $M W$ of pyridine is $79.1 \mathrm{~g} / \mathrm{mol}$.

\subsection{Catalytic Performance in ODS-DBT}

The model compound dibenzothiophene (DBT) was dissolved into $\mathrm{n}$-hexane to make a $500 \mathrm{ppm}$ stock solution. The oxidative desulfurization experiment was performed in a threenecked $500 \mathrm{~mL}$ round-bottomed flask equipped with a condenser fitted with a magnetic stirrer and immersed in an oil bath controlled by a

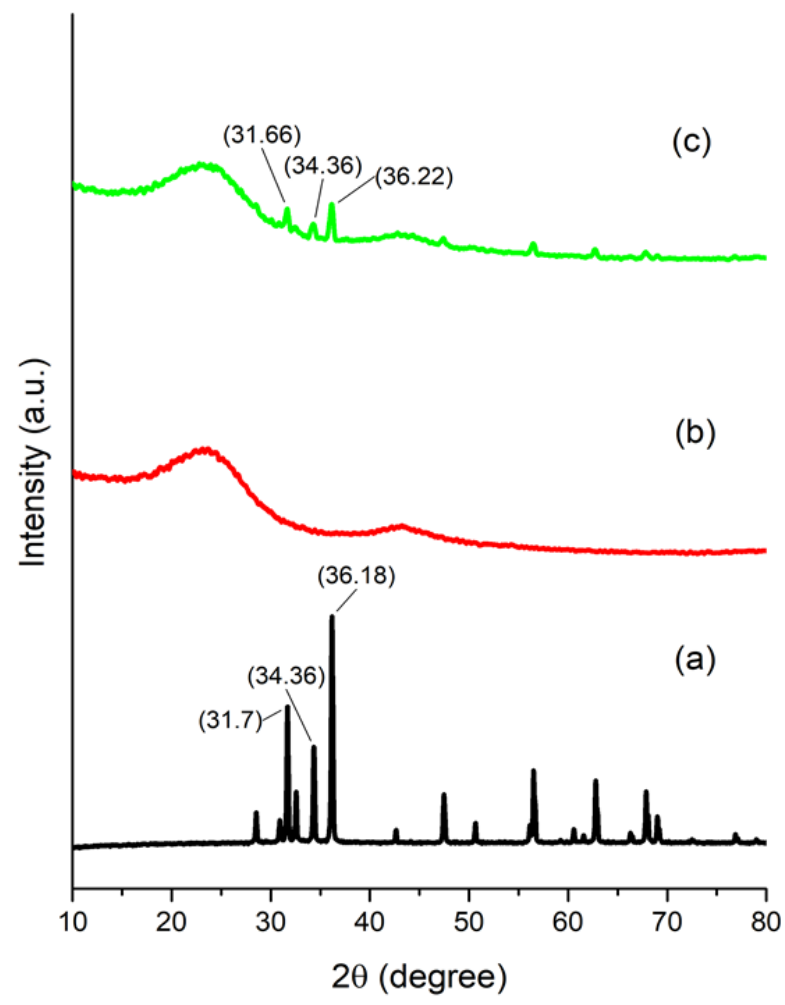

Figure 1. X-ray diffractogram of (a) $\mathrm{ZnO}$, (b) $\mathrm{AC}$, and (c) $\mathrm{ZnO}-\mathrm{AC}$.

Table 1. Properties of the $\mathrm{ZnO}, \mathrm{AC}$, and $\mathrm{ZnO}$-AC.

\begin{tabular}{lccccc}
\hline Catalysts & $\begin{array}{c}\text { BET Surface } \\
\text { Area }\left(\mathrm{m}^{2} / \mathrm{g}\right)\end{array}$ & $\begin{array}{c}\text { Pore Volume } \\
\left(\mathrm{cm}^{3 / \mathrm{g}}\right)\end{array}$ & $\begin{array}{c}\text { Pore Diameter } \\
(\mathrm{nm})\end{array}$ & $\begin{array}{c}\text { Crystallite } \\
\text { Size }(\mathrm{nm})\end{array}$ & $\begin{array}{c}\text { Acidity } \\
(\mathrm{mmol} / \mathrm{g})\end{array}$ \\
\hline $\mathrm{ZnO}$ & 7.38 & 0.029 & 7.798 & 39.295 & 1.9083 \\
$\mathrm{AC}$ & 695.971 & 0.334 & 5.199 & - & 3.9355 \\
$\mathrm{ZnO}-\mathrm{AC}$ & 734.351 & 0.382 & 5.313 & - & 4.8780 \\
\hline
\end{tabular}

thermometer. The mixture of the dibenzothiophene $(20 \mathrm{~mL})$ and the catalyst $(0.1 \mathrm{~g})$ was then introduced and heated under vigorous stirring. Once the temperature was attained at $60{ }^{\circ} \mathrm{C}, 0.1 \mathrm{~mL}$ of $30 \%$ aqueous solution of $\mathrm{H}_{2} \mathrm{O}_{2}$ as oxidant was introduced for $2 \mathrm{~h}$ under stirring. The oxidized DBT solution was then transferred to a separating funnel followed by the addition of extraction solvent (acetonitrile) and extracted with the volume ratio of the total solvent to oxidized ODS solution was 1:1. The amount of the remaining DBT in $\mathrm{n}$-hexane was measured using a UV-Vis spectrophotometer at the wavelength of $235 \mathrm{~nm}$ to determine the efficiency of DBT removal. The removal percentage of DBT is calculated based on equation (2).

$$
(\%)=\frac{C_{0}-C_{t}}{C_{0}} \times 100
$$

where $C_{0}$ is the DBT initial concentration in the stock solution and $C_{t}$ is the DBT concentration of the oxidized DBT solution in the nhexane layer after reaction time $(t)$.

\section{Results and Discussions}

\subsection{Catalyst Characterization}

The XRD patterns of $\mathrm{ZnO}, \mathrm{AC}$, and $\mathrm{ZnO}-\mathrm{AC}$ samples were recorded at $2 \theta$ between $10^{\circ}$ to $80^{\circ}$. The $\mathrm{Cu} \mathrm{K} \alpha$ radiation operates at $40 \mathrm{kV}$ and $30 \mathrm{~mA}$ with $\lambda=1.54 \AA$. Figure 1 shows the XRD patterns of $\mathrm{ZnO}, \mathrm{AC}$, and $\mathrm{ZnO}$-AC. In Figures 1(a), the three main diffraction peaks were observed at $31.7^{\circ}$ (hkl plane of 100), $34.5^{\circ}$ (hkl plane 002), and $36^{\circ}$ (hkl plane of 101) that correspond to the wurtzite structure of $\mathrm{ZnO}$ with diffraction data also showed good agreement with JCPDS Data Card No: 36-1451 [19]. For Figure 1(b) and (c), the diffraction profiles exhibited broad peaks at $2 \theta$ around $24^{\circ}$ and $42^{\circ}$ was assigned to the reflection from (002) and (100) planes, respectively [18]. The $\mathrm{ZnO}$ structure does change after blended with $90 \mathrm{wt} \% \mathrm{AC}$ suggesting the blending process was successful. It can be seen that the blending $\mathrm{ZnO}$ with $\mathrm{AC}$ could increase the crystallinity of AC. This proves that blending $\mathrm{ZnO}$ with $\mathrm{AC}$ can remove the amorphous phase of $\mathrm{AC}$ so that the crystal character is purer. Scherrer's formula [20] was used to calculate the crystallite size of the $\mathrm{ZnO}$, 
$\mathrm{AC}$, and $\mathrm{ZnO}-\mathrm{AC}$ which was observed in Table 1.

The surface area and porosity properties of $\mathrm{ZnO}, \mathrm{AC}$, and $\mathrm{ZnO}-\mathrm{AC}$ were also shown in $\mathrm{Ta}$ ble 1 . The $\mathrm{ZnO}-\mathrm{AC}$ sample possesses an average $(\mathrm{BJH})$ pore size of $5.313 \mathrm{~nm}$, which corresponds rather well to the pore size of the initial $\mathrm{AC}$ used as a support material. According to the BET evaluation, $\mathrm{ZnO}-\mathrm{AC}$ has a higher surface area of $734.351 \mathrm{~m}^{2} / \mathrm{g}$ compared to $\mathrm{ZnO}$ and $\mathrm{AC}$ themselves. It can be seen that $\mathrm{AC}$ blending with $10 \mathrm{wt} \%$ of $\mathrm{ZnO}$ does not block the $\mathrm{AC}$ pores, instead, it increased the porosity of $\mathrm{AC}$ as a support material. This positive contribution of $\mathrm{ZnO}$ dispersion was quite astonishing for physical blending, where no solvent was involved during the blending method, however

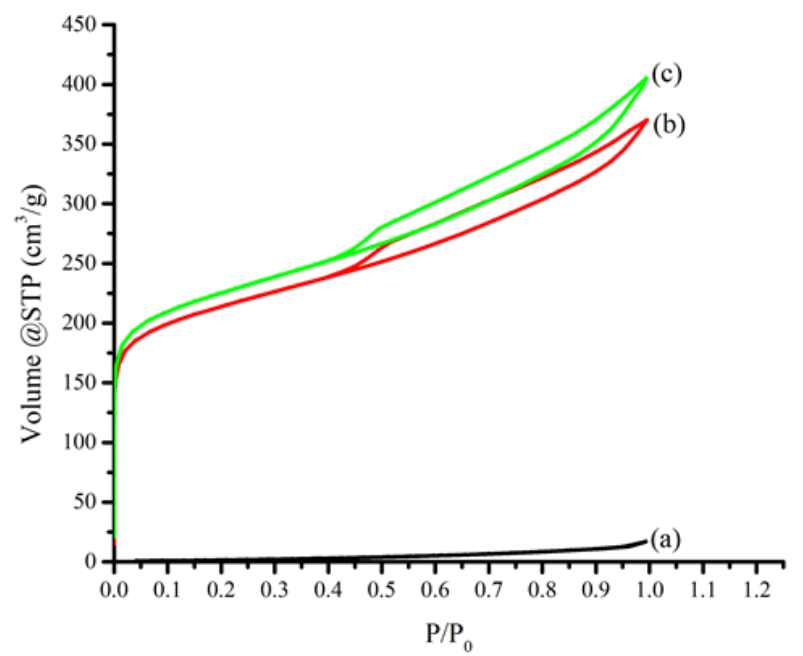

$\mathrm{AC}$ was still able to disperse $\mathrm{ZnO}$ in a homogenous manner. The good dispersion of $\mathrm{ZnO}$ across the AC support would ultimately affect its performance in ODS reaction, as this reaction required a catalyst with a high surface area.

Pore characteristics of the $\mathrm{ZnO}, \mathrm{AC}$, and $\mathrm{ZnO}$-AC were determined by $\mathrm{N}_{2}$ adsorptiondesorption measurement as illustrated in Figure $2 . \mathrm{ZnO}$ was found to be of Type III in nature as per the IUPAC classification that describes adsorption on macroporous adsorbents with weak adsorbate-adsorbent interactions [21]. The typical IV (a) curve accompanied with an $\mathrm{H} 3$ type hysteresis loop was observed in the isotherms of $\mathrm{AC}$ and $\mathrm{ZnO}-\mathrm{AC}$, indicating the predominance of mesopores [22]. The presence

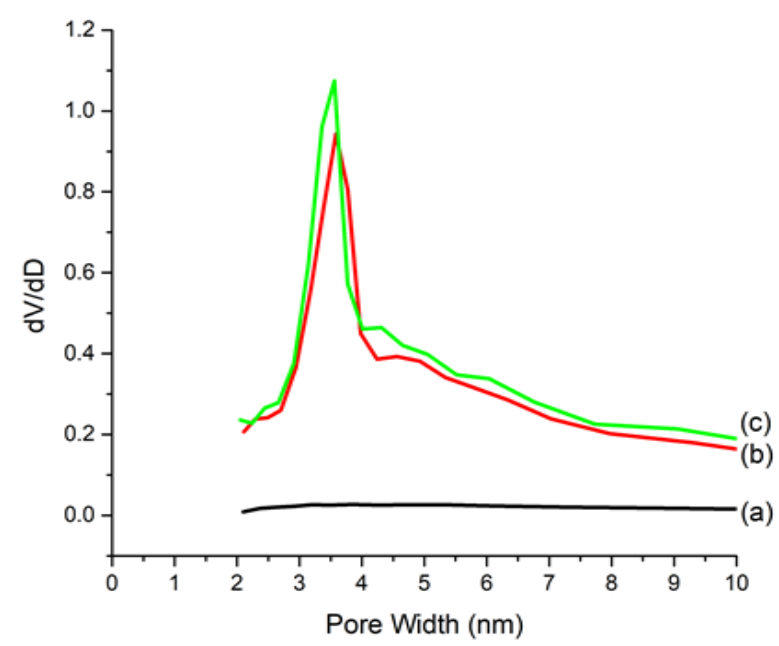

Figure 2. $\mathrm{N}_{2}$ adsorption-desorption isotherm (left side) and Pore size distribution (right side) of (a) $\mathrm{ZnO}$, (b) $\mathrm{AC}$, and (c) $\mathrm{ZnO}-\mathrm{AC}$.
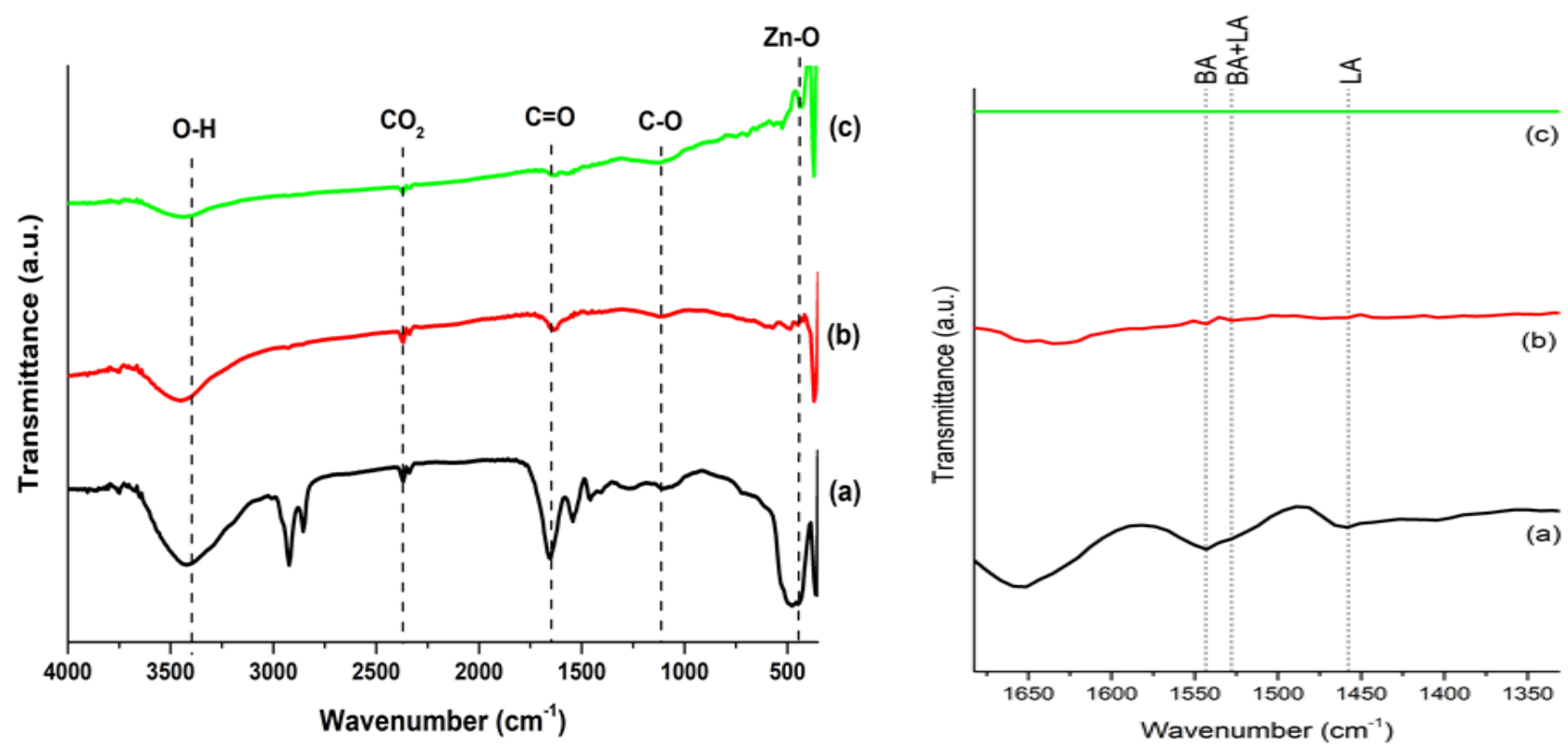

Figure 3. FTIR spectra after pyridine adsorption of (a) $\mathrm{ZnO}$, (b) AC, and (c) $\mathrm{ZnO}$-AC in normal size (left side) and enlarged size (right side). 
of mesopores in the $\mathrm{ZnO}, \mathrm{AC}$, and $\mathrm{ZnO}-\mathrm{AC}$ was also indicated by the pore size distribution as depicted in Figure 2.

The acidity value of the catalysts was determined gravimetrically using pyridine vapor, which is shown in Table 1. As the $\mathrm{ZnO}$ blended into AC, its acidity increased. These properties could be owed to the good dispersion of $\mathrm{ZnO}$ across AC, which was mentioned earlier in the porosity properties section. The amount of acid sites is crucial in ODS as the catalyst serves as a polyacid. In ODS, acid sites of catalysts are required for DBT conversion into sulfoxides and sulfones. The Brønsted and Lewis acid sites of each catalyst could be seen in Figure 3 in an enlarged size. The vibration band appearing at $1550 \mathrm{~cm}^{-1}$ is assigned to Brønsted (B) acid sites, whereas the vibration band at 1450 $\mathrm{cm}^{-1}$ is attributed exclusively to Lewis (L) acid sites. The band observed at $1525 \mathrm{~cm}^{-1}$ is due to both Brønsted and Lewis (B+L) acidic sites [23]. The figure also shows an absorption band at about $3400 \mathrm{~cm}^{-1}$ which refers to the stretching vibration of the $\mathrm{O}-\mathrm{H}$ bond originating from water molecules adsorbed on the sample surface. The peak of stretching $\mathrm{C}=\mathrm{O}$ between $1600-1700 \mathrm{~cm}^{-1}$ and stretching of $\mathrm{C}-\mathrm{O}$ asym-
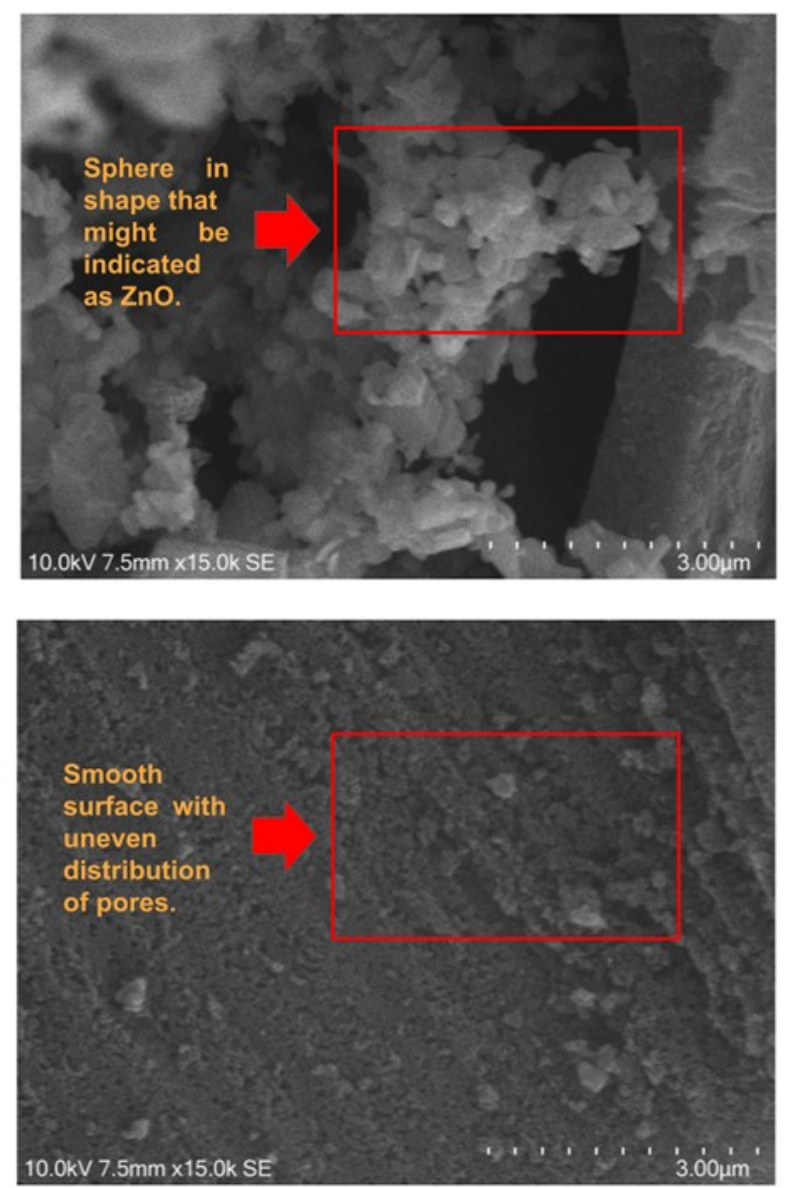

Figure 4. SEM micrographs of ZnO-AC. metry between $1200-1300 \mathrm{~cm}^{-1}$ were also evident. The band observed at about $2300 \mathrm{~cm}^{-1}$ is associated with a $\mathrm{C}=\mathrm{O}$ stretching mode which may be due to $\mathrm{CO}_{2}$ absorption from water. The absorption band observed at $420-430 \mathrm{~cm}^{-1}$ is associated with the characteristic vibrational mode of the $\mathrm{Zn}-\mathrm{O}$ bond. The results of this study are following previous research [24].

The surface morphology of $\mathrm{ZnO}-\mathrm{AC}$ is illustrated in Figure 4. The SEM micrograph showed a smooth surface with uneven distribution of pores. It was also shown some sphere in shape that might be indicated as ZnO. SEM image shows $\mathrm{ZnO}$ particles were spherical and agglomerated. Meanwhile, the morphology of $\mathrm{AC}$ exhibited fiber-like and porous with plenty of grain boundaries. The pores were indicating the availability of catalytic sites for desulfurization to take place [25]. Energy dispersive Xray (EDX) analysis was also conducted on the $\mathrm{ZnO}-\mathrm{AC}$ sample. The blending $\mathrm{ZnO}$ with $\mathrm{AC}$ was succeeded indicated by the amount of $\mathrm{Zn}$ (13 wt\%), O (4 wt\%), and C (83 wt\%) presence in the sample. Based on these results, this material does not contain any impurities.

\subsection{Oxidative Desulfurization of Dibenzothio- phene}

The remaining dibenzothiophene (DBT) concentration was determined by a UV-Vis spectrophotometer. The absorption at $235 \mathrm{~nm}$ was used to monitor the DBT concentration as the maximum absorbance in this molecule due to its chromophore functional group. The efficiency of ODS-DBT in percentage is shown in Table 2. A synergistic effect between $\mathrm{ZnO}$ and $\mathrm{AC}$ was observed in improving the efficiency of ODS-DBT, in which both single $\mathrm{ZnO}$ and $\mathrm{AC}$ gave lower efficiency of ODS-DBT. The efficiency of ODS-DBT was found to increase by blending $\mathrm{ZnO}$ with $\mathrm{AC}$ and it is believed due to the good dispersity of the combined $\mathrm{ZnO}$-AC catalyst, as this was also confirmed by its higher surface area and acidity. Besides, the efficiency of $\mathrm{ZnO}-\mathrm{AC}$ is further improved by the adsorptive capability of $\mathrm{ZnO}$ and $\mathrm{AC}$ themselves that assist in increasing the possible contact between DBT with catalyst active sites. Indeed, the introduction of $\mathrm{ZnO}$ to $\mathrm{AC}$ contributes to

Table 2. Catalytic ODS performance of $\mathrm{ZnO}$, $\mathrm{AC}$, and $\mathrm{ZnO}-\mathrm{AC}$ catalysts.

\begin{tabular}{cc}
\hline Catalyst & The efficiency of ODS-DBT (\%) \\
\hline $\mathrm{ZnO}$ & 71.04 \\
$\mathrm{AC}$ & 91.26 \\
$\mathrm{ZnO}-\mathrm{AC}$ & 93.83 \\
\hline
\end{tabular}


the increment of the contact surface area of the catalyst, which subsequently increasing the sulfur removal efficiency. Although in this case, it does not have a significant effect because its weight percentage is small compared to AC, which is 1:9. Compared to the literature, the results of previous studies revealed that $\mathrm{ZnO}-\mathrm{AC}$ was able to remove sulfur up to about $85 \%$ [15] and $75 \%$ [17]. Thus, it can be concluded that the $\mathrm{ZnO}$-AC catalyst that we prepared through the physical blending technique is so potent that it provides a desulfurization efficiency of more than $90 \%$.

The catalytic data in Figure 5 clearly show that the DBT removal efficiency increases with an increment of reaction time. However, insignificant sulfur removal was witnessed after 120 min of reaction time exceeding to longest tested time; $150 \mathrm{~min}$. It is anticipated that at prolong reaction time of more than $120 \mathrm{~min}$, it does not have much effect on the proportion of desulfurization due to the degradation of most oxidants. Quantitative analysis through titration method discovered that most of $\mathrm{H}_{2} \mathrm{O}_{2}$ were utilized after reaction, either through selective utilization or unselective utilization due to (i) decomposition to oxygen and water, (ii) hydrogenation to water, and (iii) direct non-selective formation of water [26].

\section{Conclusions}

The physical blending technique proved to be effective for the synthesis of $\mathrm{ZnO}$-AC. This is evidenced by the specific surface area and acidity of $\mathrm{ZnO}-\mathrm{AC}$ which are higher than $\mathrm{ZnO}$ and $\mathrm{AC}$, which indicates the homogeneity of the distribution of $\mathrm{ZnO}$ nanoparticles on the $\mathrm{AC}$ surface. With these characteristics, this catalyst can produce of DBT removal of $93.83 \%$ with an ODS reaction time of 120 minutes.

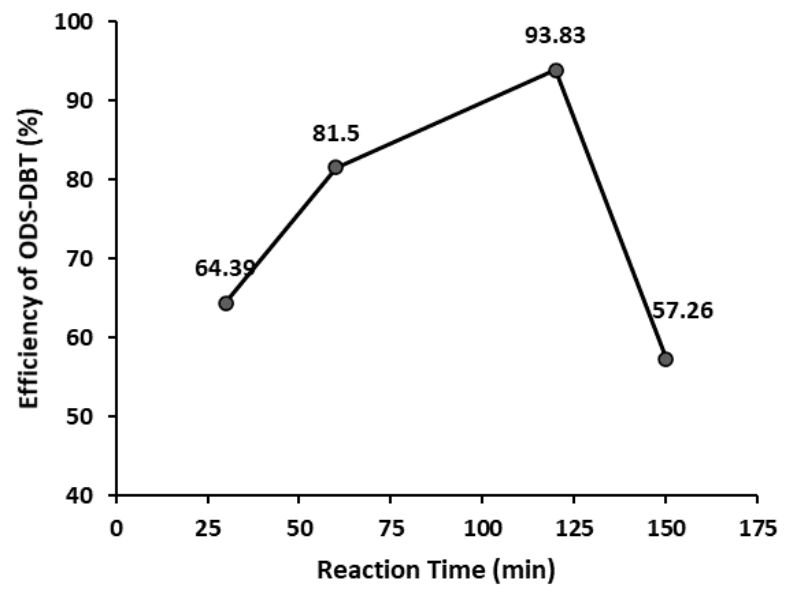

Figure 5. Effect of reaction time on ODS-DBT of $\mathrm{ZnO}$-AC catalyst.

\section{Acknowledgments}

This work was supported by The Research Program for the Indonesia Collaboration (Program Penelitian Kolaborasi IndonesiaPPKI) 2020 between Sebelas Maret University, Gadjah Mada University, and Sepuluh Nopember Institute of Technology under contract number of 514/UN27.21/HK/2020.

\section{References}

[1] Tripathi, D., Singh, R.K. (2021). Oxidative desulfurization of dibenzothiophene using cobalt(II) complexes with substituted salen-type ligands as catalysts in model fuel oil. Catalysis Letters, 151, 713-719. DOI: 10.1007/s10562-020-03343-4

[2] Ghubayra, R., Yahya, R., Kozhevnikova, E.F., Kozhevnikov, I.V. (2021). Oxidative desulfurization of model diesel fuel catalyzed by carbon-supported heteropoly acids: Effect of carbon support. Fuel, 301, 121083. DOI: 10.1016/j.fuel.2021.121083.

[3] Chen, L., Hu, Z., Ren, J., Wang, Z., Yuan, Z. (2021). Efficient oxidative desulfurization over highly dispersed molybdenum oxides supported on mesoporous titanium phosphonates. Microporous and Mesoporous Materials, $\quad 315, \quad 110921$. D O I : 10.1016/j.micromeso.2021.110921

[4] Zhang, X., Song, H., Sun, C., Chen, C., Han, F., Li, X. (2019). Photocatalytic oxidative desulfurization and denitrogenation of fuels over sodium doped graphitic carbon nitride nanosheets under visible light irradiation. Materials Chemistry and Physics, 226, 34-43. DOI: 10.1016/j.matchemphys.2019.01.011

[5] Dana, M., Sobati, M.A., Shahhosseini, S., Ansari, A. (2020). Optimization of a continuous ultrasound-assisted oxidative desulfurization (UAOD) process of diesel using response surface methodology (RSM) considering the operating cost. Chinese Journal of Chemical Engineering, 28(5), 1384-1396. DOI: 10.1016/j.cjche.2019.12.007

[6] Wang, C., Chen, Z., Zhu, W., Wu, P., Jiang, W., Zhang, M., Li, H., Zhu, W., Li, H. (2017). One-pot extraction and oxidative desulfurization of fuels with molecular oxygen in lowcost metal-based ionic liquids. Energy \& Fuels, 31(2), 1376-1382. DOI: 10.1021/acs.energyfuels.6b02624

[7] Xiao, J., Wu, L., Wu, Y., Liu, B., Dai, L., Li, Z., Xi, H. (2014). Effect of gasoline composition on oxidative desulfurization using a phosphotungstic acid/activated carbon catalyst with hydrogen peroxide. Applied Energy, $113, \quad 78-85$. D O I : 10.1016/j.apenergy.2013.06.047 
[8] Guo, J.-X., Fan, L., Peng, J.-F., Chen, J., Yin, H.-Q., Jiang, W.-J. (2014). Desulfurization activity of metal oxides blended into walnut shell-based activated carbons. Journal of Chemical Technology \& Biotechnology, 89(10), 1565-1575. DOI: 10.1002/jctb.4240

[9] Adeyi, A., Adekanmi, A., Aberuagba, \& Folorunsho. (2012). Comparative Analysis of Adsorptive Desulphurization of Crude Oil by Manganese Dioxide and Zinc Oxide. Research Journal of Chemical Sciences, 2(8), 14-20.

[10] Nekouei, F., Nekouei, S. (2017). Comparative study of photocatalytic activities of $\mathrm{Zn}_{5}(\mathrm{OH})_{8} \mathrm{Cl}_{2} \cdot \mathrm{H}_{2} \mathrm{O}$ and $\mathrm{ZnO}$ nanostructures in ciprofloxacin degradation: Response surface methodology and kinetic studies. Science of the Total Environment, 601-602, 508-517. DOI: $10.1016 /$ j.scitotenv.2017.05.117

[11] Nawaf, A.T., Jarullah, A.T., Abdulateef, L.T. (2019). Design of a synthetic zinc oxide catalyst over nano-alumina for sulfur removal by air in a batch reactor, Bulletin of Chemical Reaction Engineering \& Catalysis, 14(1), 7992. DOI: $10.9767 /$ bcrec.14.1.2507.79-92

[12] Riad, M., Mikhail, S. (2012). Oxidative desulfurization of light gas oil using zinc catalysts prepared via different techniques. Catalysis Science \& Technology, 2, 1437-1446. DOI: 10.1039/C2CY20064C

[13] Yu, G., Lu, S., Chen, H., Zhu, Z. (2005). Oxidative Desulfurization of Diesel Fuels with Hydrogen Peroxide in the Presence of Activated Carbon and Formic Acid. Energy \& Fuels, 19, 447-452. DOI: 10.1021/ef049760b

[14] Khalil, L.B., Girgis, B.S., Tawfik, T.A. (2001). Decomposition of $\mathrm{H}_{2} \mathrm{O}_{2}$ on activated carbon obtained from olive stones. Journal of Chemical Technology \& Biotechnology, 76(11), 11321140. DOI: $10.1002 /$ jctb.481

[15] Swat, A.A.A., Saleh, T.A., Ganiyu, S.A., Siddiqui, M.N., Alhooshani, K.R. (2017). Preparation of activated carbon, zinc oxide, and nickel oxide composites for potential application in the desulfurization of model diesel fuels. Journal of Analytical and Applied Pyrolysis, 128, 246-256. DOI: 10.1016/j.jaap.2017.10.004

[16] AhmedZaki, N.S., Ali, S.M., Al-Karkhi, S.R. (2017). Investigation Desulfurization Method using Air and Zinc Oxide/Activated Carbon Composite. Iraqi Journal of Chemical and Petroleum Engineering, 18(91), 37-46.

[17] Khlaif, T.H., Bded, A.S., Salman, M.D. (2020) Sulfur Reduction of Crude Oil Using Zinc Oxide Nanoparticles Loaded Activated Carbon as Adsorbent. Journal of Critical Reviews, 7(17), 1884-1890. DOI: 10.31838/jcr.07.17.236
[18] Prahas, D., Kartika, Y., Indraswati, N., Ismadji, S. (2008). Activated carbon from jackfruit peel waste by $\mathrm{H}_{3} \mathrm{PO}_{4}$ chemical activation: Pore structure and surface chemistry characterization. Chemical Engineering Journal, $140(1-3), \quad 32-42$. D O : 10.1016/J.CEJ.2007.08.032

[19] Yedurkar, S., Maurya, C., Mahanwar, P. (2016). Bio-synthesis of Zinc Oxide Nanoparticles Using Ixora Coccinea Leaf Extract-A Green Approach. Open Journal of Synthesis Theory and Applications, 5, 1-14. DOI: 10.4236/ojsta.2016.51001

[20] Khanna, L., Verma, N.K. (2013). Sizedependent magnetic properties of calcium ferrite nanoparticles. Journal of Magnetism and Magnetic Materials, 336, 1-7. DOI: 10.1016/J.JMMM.2013.02.016

[21] Donohue, M.D., Aranovich, G. (1998). Classification of Gibbs adsorption isotherms. Advances in Colloid and Interface Science, 76$77, \quad 137-152$. DOI: 10.1016/s00018686(98)00044-x

[22] Neena, D., Kondamareddy, K.K., Bin, H., Lu, D., Kumar, P., Dwivedi, R.K., Pelenovich, V.O., Zhao, X., Gao, W., Fu, D. (2018). Enhanced visible-light photodegradation activity of $\mathrm{RhB} / \mathrm{MB}$ from aqueous solution using nanosized novel Fe-Cd co-modified $\mathrm{ZnO}$. Scientific Reports, 8(1), 10691. DOI: 10.1038/s41598-018-29025-1

[23] Viswanadham, B., Singh, S., Friedrich, H.B., Mahomed, A.S. (2018). The Role of Bronsted and Lewis Acidity in the Green Synthesis of Homopropargyl Alcohols over HZSM-5. South African Journal of Chemistry, 71, 62-67. DOI: $10.17159 / 0379-4350 / 2018 / v 71 a 8$

[24] Abdul-Kadhim, W., Deraman, M.A., Abdullah, S.B., Tajuddin, S.N., Yusoff, M.M., Taufiq-Yap, Y.H., Rahim, M.H.A. (2017). Efficient and reusable iron-zinc oxide catalyst for oxidative desulfurization of model fuel. Journal of Environmental Chemical Engineering, 5, 1645-1656. DOI: 10.1016/j.jece.2017.03.001

[25] Loo, W.W., Pang, Y.L., Wong, K.H., Lim, S., Mah, S.K. (2018). Adsorption-photocatalysis of organic dyes using empty fruit bunch activated carbon-metal oxide photocatalyst. IOP Conference Series: Materials Science and Engineering, 458, 012042. DOI: 10.1088/1757$899 \mathrm{x} / 458 / 1 / 012042$.

[26] Samanta, C. (2008). Direct synthesis of hydrogen peroxide from hydrogen and oxygen: An overview of recent developments in the process. Applied Catalysis A: General, 350(2), $\begin{array}{lllllllllll} & 3 & 3 & - & 1 & 4 & 9 & & \text { D } & \text { O } & \text { I }\end{array}$ : 10.1016/J.APCATA.2008.07.043. 